\title{
Sonata Form in the Nineteenth-Century Symphony
}

\author{
STEVEN CRAIG CANNON \\ University of Saskatchewan
}

\begin{abstract}
This paper presents an analytical survey of 283 symphonies dating from 1800-1899. Features of full symphonies include the rate of compositional output over the course of the century, the number, order, and keys of movements, and the prevalence of sonata form. Individual movements that use sonata form receive greater attention, including analysis of the general proportions of internal sections (that is, relative lengths of slow introductions, expositions, developments, and recapitulations plus codas), as well as overall tonal plans.
\end{abstract}

Submitted 2015 September 15; accepted 2016 March 1.

KEYWORDS: symphonies, sonata form, recapitulation, nineteenth century

THE present corpus study was originally part of an investigation into how dynamic markings and instrumentation influence the function of recapitulatory onsets in sonata form. To determine which compositional strategies are most typical at the moment of return, I undertook an analytical survey of sonata-form movements in nineteenth-century symphonies, focusing mostly on the boundary between the development and the recapitulation. During this research, however, several interesting features that do not specifically relate to the project's main topic drew my attention. For example, the analysis includes data on movement order, tonal plans, and the locations of other formal boundaries within movements. Since I already present the main findings of the larger project on recapitulations elsewhere (Cannon, 2015a, 2015b), here I give a more general account of those other, more general features of the symphonic repertoire.

Before presenting the results of the analytical survey, I first describe the corpus, then outline my analytical method. The description of survey results divides into two parts: an account of features across full symphonic cycles and analysis of movements that use sonata form.

\section{CORPUS}

I define the boundaries of the corpus by three main factors: time period, genre, and availability of scores. The year 1800-when Beethoven completed his first symphony —is an obvious starting point. The end date is somewhat arbitrary: I chose the year 1899 simply because it rounds out an even hundred years. This end date also falls nicely between the oeuvres of two other important symphonists: Bruckner completed his last symphony in 1896, and Sibelius wrote his first in 1899. In terms of genre, I include only works titled "Symphony" (or an equivalent term in another language). I omit, however, works from other similar genres such as concertos, serenades, sinfonias concertante, symphonic poems or paintings, symphonic fantasies, toy symphonies, concert overtures, symphonic suites, and symphonic music excerpted from operas, ballets, and other dramatic works.

To my knowledge, no scholar has ever attempted a complete list of all symphonies composed in the Romantic era, and such a task is indeed well beyond the scope of my project. One study that approaches the topic is Frank Kirby's (1995) list of 391 symphonies, which only covers works published in Germanspeaking lands. Focusing on just 1850-1875, Rebecca Grotjahn (1998) lists 507 new symphonic concert works by 238 different composers. In addition to symphonies, her list includes other orchestral genres. In these lists, both Kirby and Grotjahn include works for which no scores survive. Julian Horton's (2013) overview of inter-movement key relationships in nineteenth-century symphonies is also quite large, comprising 163 symphonies by 34 composers. For works from before 1840, The Symphony 1720-1840, a collection of scores printed by Garland Publishing (Brook 1986), provides extensive works lists and thematic indexes. Keyword searches of the Hofmeister Monatsberichte, a series that appeared from 1829 to 1900 cataloging newly published music (Hofmeister 2008), yielded titles of many symphonies that do not 
often receive critical comment. The Symphonic Repertoire, a series of books begun by A. Peter Brown (2002-2012), includes lists of symphonies composed in various regions in Europe. Christopher Fifield's (2015) survey of German symphonies in the middle of the nineteenth century offers analysis of several lesser-known works.

It is, however, impossible to say exactly how many symphonies were composed during the nineteenth century. In his introduction to the reference volume of The Symphony 1720-1840, Barry S. Brook (1986, p. xx) estimates that as many as 20,000 symphonies were composed in the period covered by that collection. This number seems rather large at first glance, but he uses a broader generic categorization than my survey, including other orchestral genres. Moreover, composers wrote fewer symphonies, but of greater length, in the Romantic era than in the Classical (compare Haydn's 108 numbered symphonies to Beethoven's 9). In perusing resources such as The Symphony 1720-1840, the Hofmeister Monatsberichte, Kirby's work, Grotjahn's list, and The Symphonic Repertoire, I have noticed references to more than 450 symphonists active during the nineteenth century, composing over 1200 symphonies. Taking into account unpublished works, as well as the many composers who must have escaped my notice, it seems plausible that the years 1800-1899 may have seen the composition of around 2000 to 2500 symphonies.

For practical reasons, I only examine symphonies with scores that were easily available to me at the time that I did the preliminary research for this project.[1] That is, I include all nineteenth-century symphonies whose scores were either held in the Marvin Duchow Music Library at McGill University, or were available online from the Petrucci Music Library, run by the International Music Scores Library Project. I limit the study to these two collections in order to keep the project to a manageable size. Other scores may be available online from other sources-indeed, many more scores have since appeared on IMSLP - but I feel the corpus is large enough already. In total, it comprises 283 symphonies dating from 1800-1899 by 136 different composers. In total, the 283 symphonies have 1031 movements, 483 of which I deem to be clear examples of sonata form. For full details on the works, see the supplementary spreadsheets associated with this paper at http://hdl.handle.net/1811/79827. [2]

My analysis focuses mainly on movements that clearly align with sonata form in the strictest sense of the term-that is, Hepokoski and Darcy's (2006) “Type 3," and in some cases also their "Type 2.” As such I do not include concerto, rondo, sonata without development (Hepokoski and Darcy's "Type 1"), large ternary, and small ternary (or rounded binary), even though these forms all relate to sonata. One related form that I do include in the survey is the sonata without recapitulation of the main theme (Hepokoski and Darcy's “Type 2”). The point at which correspondence with the exposition begins varies in such movements, and this topic deserves attention.

For scherzos and some finales, the classification of form type is by no means straightforward. In the case of scherzos (or minuets), a large-scale A-B-A ternary form most typically contains an opening scherzo that uses a small ternary (also called rounded binary) or small binary form (Caplin, 1998, pp. 219230). The difference, however, between small ternary and sonata is more of a continuum than a clear-cut distinction (Jurkowski, 2010), and in many cases I am reluctant to categorize a scherzo or a trio into one formal type or another. Since this classification ultimately determines whether the movement's internal structure should be subject to more detailed analysis, I decided that the best solution would be to exclude scherzos that make use of the large ternary, regardless of whether the internal sections use sonata form. If the movement as a whole, however, appears to be a sort of sonata form, I analyze it in as much depth as other sonata-form movements.

Finales involve another sort of formal continuum: one between sonata form and rondo form. Depending on the movement, and the perspective of the analyst, the rondo aspect or sonata aspect may be more salient (Hepokoski \& Darcy, 2006, p. 330). Although I generally avoid inclusion of sonata-rondos in the survey, some may have slipped in if one of the refrains seems to function more obviously as the beginning of the recapitulation than the others.

\section{ANALYTICAL METHOD}

In order to deal with such a large number of movements, the analysis takes the form of simple comments and notes. I record the information in an Excel spreadsheet to allow easy interpretation of the data. The large scale of this project allows only a superficial analysis of each movement. Whenever possible I consult published analyses, but before recording any details in the spreadsheet, I always verify them directly in the score. During the score analysis, I only look at the passages for which I am recording information: the onset of the exposition, the end of the exposition, the end of the development section, the beginning of the 
recapitulation, and the end of the movement. While this method gives a rather incomplete picture of an individual movement, it allows the study to cover a very large number of pieces. Although most of the types of information are simple enough, explanations of a few details are helpful: my method for determining dates, my classification of movement types, and a description of the shortcomings of the analytical method.

\section{Dates}

For symphonies that took several years to compose, I only use the latest year by which the symphony was complete. For symphonies with multiple versions, I tend to use the last version. If a date of composition is unknown, I substitute the date of first publication or the date of first performance.

\section{Movement Types}

Not all symphonies follow the typical four-movement fast-slow-scherzo-finale pattern, so in addition to numbering the movements, I also assign a movement type. I categorize movements into six types based on ordering and tempo: first fast, slow, scherzo, finale, only, and unconventional.

First Fast refers to the movement in a relatively quick tempo that begins most symphonies. The first movement is usually a sonata form, but movements that use other forms may fall into this type if they have a fast tempo and are placed at the beginning of a symphony. While slow introductions often precede the first movement, in eighteenth-century symphonies a full, independent slow movement very occasionally bumps the sonata allegro into second position. Among the nineteenth-century works that make up the corpus, however, only one work places the generic first fast movement in second position: RimskyKorsakov's Symphony No. 2, "Antar," has a movement with multiple tempos preceding the allegro movement.

Slow movements usually occur in second (or sometimes third, and in eighteenth-century works occasionally first) place in a four-movement cycle, and symphonies with five or more movements may have more than one slow movement. Scherzos are usually in third place (but occasionally in second) in a four-movement cycle. I include in this category not only movements labelled "Scherzo" or "Minuet" by the composer, but also any other internal movement that uses a dance (or sometimes march) idiom. Symphonies with five or more movements may have more than one such "dance" or "scherzo" movement. I use the term finale for the last movement in most symphonies, unless it is obviously a minuet or scherzo.

Some symphonies, especially by Italian composers at the beginning of the nineteenth century, have only one movement, and I place these movements in their own category: only. Despite their possible generic connection to overtures and sinfonias for dramatic or liturgical settings, I include them in my survey because they are titled "symphony" or "sinfonia."

Although I define the above types as broadly as possible, some movements, especially in symphonies with programmatic qualities, defy categorization. Such movements, which I label unconventional, have enough internal tempo changes that they are difficult to describe as slow or fast overall. If a movement with multiple tempos is the last in a cycle, however, I still label it a finale because the conventions for a finale's tempo are more flexible than for earlier movements.

\section{Information Not Included in Analysis}

Because I keep the analysis simple enough to cover such a large corpus, many details are absent. I ignore, for instance, the internal structure of the exposition and recapitulation, as well as the internal structure of the development section and the entire coda. The onset of the coda could, however, also be a useful data point for describing the dimensions of sonata form. The slow introduction and the coda are external to the sonata, forming sections that fall "before the beginning" and "after the end" (Caplin, 1998, pp. 179 and 203). Since I consider the beginning of the sonata to be the joint between the slow introduction and exposition, it would make sense that the end should be the joint between the recapitulation and coda. But unlike the other major formal boundaries - especially the beginnings of the exposition and developmentthere is usually no double bar or tempo change to mark the beginning of the coda. William Caplin (1998, p. 181) writes that "the 'start' of the coda is best located at that moment when the music of the recapitulation no longer corresponds to that of the exposition, even if that moment is not perceived as a structural beginning." This type of analysis, comparing the subordinate theme(s) in the exposition and recapitulation 
measure by measure to find the precise moment where correspondence ends, is impractical for a large corpus study.

\section{FULL SYMPHONIC CYCLES}

Before dealing with sonata-form movements in more detail, I provide comments on five aspects of full symphonic cycles. First, the rate of symphonic output varies over historical time. Second, the number of movements in each symphony also varies. Third, the order in which movement types occur is fairly standard, but exceptions do arise in the repertoire. Fourth, the keys of internal movements allow for some freedom of compositional choice. And fifth, some movement types are more likely than others to use sonata form.

\section{Number of Symphonies per Decade}

During the nineteenth century, symphonies did not appear at a steady rate; instead, the number varied greatly from year to year. Figure 1 shows the number of symphonies in the corpus in each decade, with amounts ranging from only 14 in the 1840 s to as many as 45 in the 1890s. A general trend is apparent: the corpus contains more symphonies from the beginning and the end of the period but fewer from the middle, resulting in a " $U$ " shape. A mundane reason for this pattern is the availability of scores. One of the most important sources is The Symphony 1720-1840, whose end date corresponds with a sharp drop: only fourteen symphonies in the corpus date from the 1840s, compared to over 30 in most previous decades. After this point the numbers gradually increase as more recent works have had less time for scores to be lost, and as the availability of cheaper printing technology increased.

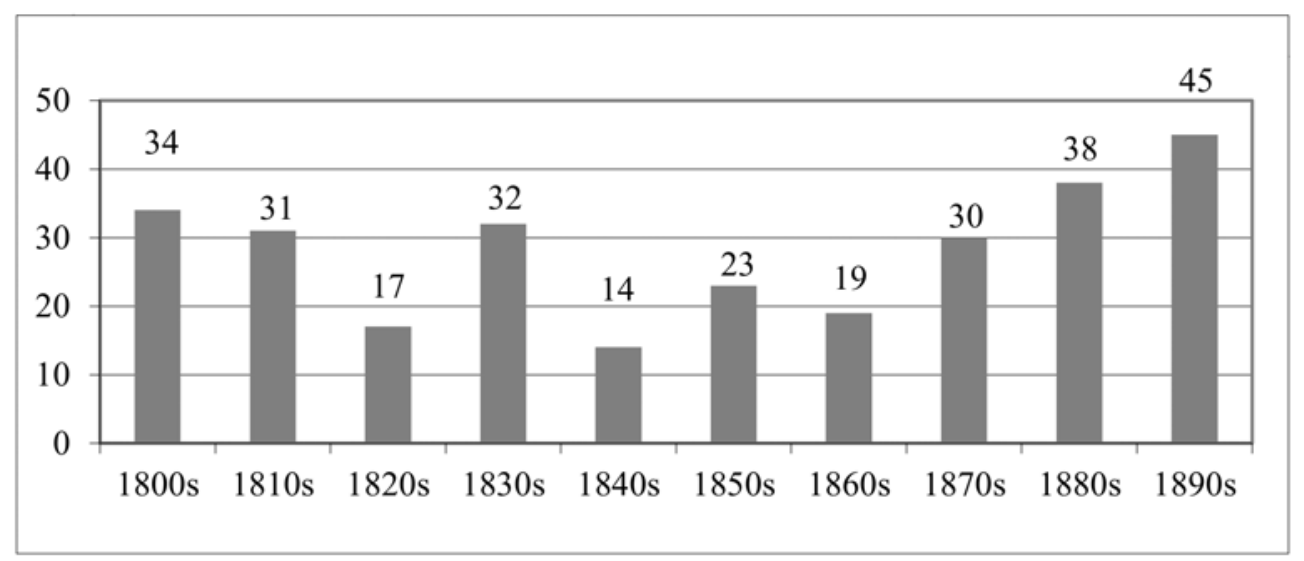

Fig. 1. Number of symphonies per decade.

There is, however, more to this pattern than a simple matter of what has survived-indeed, other scholars have already noticed this trend. Kirby's (1995) data show a profile quite similar to mine despite significant differences between our corpora. Specifically, his study includes works for which scores have not survived, he only deals with symphonies published in German-speaking lands, and he uses the date of publication rather than date of composition. Kirby goes on to quote two other authors regarding this trend: Kretzschmar (1919, p. 333) refers to "die mageren Jahre" (the lean years) starting in the 1830s, and Dahlhaus (1978, p. 36) calls the two decades following Schumann's third symphony (1850) a "tote Zeit" (dead time), followed by a second age of the symphony in the 1870s and 1880s.

Kirby offers no explanation for this decline and resurgence, but we can speculate on some possible factors, both geopolitical and artistic. On the geopolitical side, the initial decline in symphonic output may relate to the economic fallout of the Napoleonic wars. Events in the middle of the century such as the revolutions of 1848 and wars in the 1860s and 1870s may have further contributed to a climate less favorable for the production of large art works such as symphonies. Between the end of the FrancoPrussian War (1871) and the beginning of World War I (1914), however, no major international armed conflicts arose in Western Europe; this extended period of political stability and economic growth 
corresponds to an increase in symphonies at the end of the century. Moreover, as populations grew and became more urban in the wake of the industrial revolution, a concert-going "public" emerged that demanded large performance pieces such as operas and orchestral works (Taruskin, 2005). Of course, these political and economic factors only account for an increase in all genres of concert music; the reasons for the trends in symphonic output in particular are somewhat more complex.

From an artistic point of view, the increasingly high status of the symphony as an absolute art form in the middle of the century led to what Dahlhaus (1989, p. 265) calls a "crisis" for the genre, with composers only daring to attempt it "with a few works to attain the utmost limits of their art." In other words, some mid-century composers may have produced fewer symphonies because they valued quality over quantity. Another reason for the drop in symphonic production was the increased popularity of other, alternative orchestral genres. For example, Liszt's development of the symphonic poem as a new genre helped avoid simple repetition of the old forms (Dahlhaus, 1989, pp. 236-244). As the century wore on, however, such issues seem to have mattered less, and the next generation tackled the genre with gusto.

\section{Number of Movements per Symphony}

Table 1 gives a count of the symphonies in the corpus, organized into columns by the number of movements in the symphony, and into rows by decade. Four-movement symphonies are of course the norm, while symphonies with three movements are slightly more common than those with five. Of the eight two-movement symphonies, three (by Schubert, Wagner, and Borodin) are unfinished but presumably would have been conventional three- or four-movement works had they been completed. Symphonies with more than five movements are very rare: only one work has six movements (Mahler's Symphony No. 3 in D minor, 1896), one has seven (Berlioz's “Roméo et Juliette,” 1839), and one has ten (Mendelssohn's Symphony No. 2 in B-flat major, "Lobgesang," 1840). Single-movement symphonies only date from the 1800 s to the 1830s. This limited timeline relates to two factors. First, the symphony became more clearly defined as a multi-movement genre later in the century: single-movement orchestral works from after 1840 tend to be titled overtures rather than symphonies. Second, the scores of all of the single-movement symphonies in the corpus appear in the series The Symphony 1720-1840; the sudden absence of such works from after 1840 directly results from this date being the cut-off year for inclusion in that publication.

Table 1. Number of movements per symphony

\begin{tabular}{|l|l|l|l|l|l|l|l|l|}
\hline No. of movements: & 1 & 2 & 3 & 4 & 5 & 6 & 7 & 10 \\
\hline $1800 \mathrm{~s}$ & 7 & 1 & 3 & 22 & 1 & & & \\
\hline $1810 \mathrm{~s}$ & 8 & 1 & 2 & 20 & & & & \\
\hline $1820 \mathrm{~s}$ & 4 & 1 & & 11 & 1 & & & \\
\hline $1830 \mathrm{~s}$ & 8 & 1 & 1 & 20 & 1 & & 1 & \\
\hline $1840 \mathrm{~s}$ & & & 4 & 9 & & & & 1 \\
\hline $1850 \mathrm{~s}$ & & 2 & 1 & 18 & 1 & & & \\
\hline $1860 \mathrm{~s}$ & & & & 17 & 2 & & & \\
\hline $1870 \mathrm{~s}$ & & & 3 & 26 & 1 & & & \\
\hline $1880 \mathrm{~s}$ & & 1 & 3 & 32 & 2 & & & \\
\hline $1890 \mathrm{~s}$ & & 1 & 6 & 37 & 1 & 1 & & \\
\hline Grand Total & 27 & 8 & 23 & 212 & 10 & 1 & 1 & 1 \\
\hline
\end{tabular}

\section{Order of Movements}

Although the standard symphony proceeds fast-slow-scherzo-finale, other orderings are possible. Table 2 gives counts of instances of each movement type, organized into rows by the order number of the movements within the symphonic cycle, only for symphonies with three, four, or five movements. In threemovement works, the middle movement is usually slow, but occasionally it is a scherzo or minuet. Of the 212 four-movement symphonies, 152 (71.7\%) follow the standard order of movements (or, $53.9 \%$ of the total 283 symphonies in the corpus). Most of the remaining four-movement symphonies tend to have the scherzo precede the slow movement. A discrepancy in the numbers for four-movement works is worth 
noting: there are 212 four-movement symphonies but only 211 of them have a first movement because the first movement of José Nonó's Symphony in C major is lost (Shadko, 1981).

For the five-movement symphonies, three main types of movement pattern appear in the corpus. Three works have an extra scherzo (or minuet, or march) inserted between the first and second movements: Francesco Basili's Sinfonia in D minor (1828), Berlioz's "Symphonie fantastique" (1830), and Tchaikovsky's Symphony No. 3 in D major, "Polish” (1875). Inserting an extra slow movement in between the scherzo and the finale only occurs in later works: the three examples in the corpus are Giovanni Sgambati's Symphony No. 1 in D major (1880), Oliver King's "Night” Symphony (1884), and Mahler's Symphony No. 2 in C minor, "Resurrection" (1894). Three symphonies from earlier in the century have a similar design, except that the extra movement is neither slow in tempo, nor a scherzo, minuet, or march; instead, an unconventional movement with possible programmatic meaning is inserted in between the scherzo and the finale: Beethoven's Symphony No. 6 in F major, "Pastoral" (1808), Schumann's Symphony No. 3 in E-flat major, "Rhenish" (1850), and Joachim Raff's Symphony No. 1 in D major, "To the Fatherland" (1861). One work, Karl Goldmark’s Symphony in E-flat major, "Country Wedding” (1860), does not fit any of the above three main patterns. It has a minuet as its second movement, followed by a scherzo for the third movement, and then a slow fourth movement.

Table 2. Order of movements

\begin{tabular}{|c|c|c|c|c|c|c|}
\hline \multirow{2}{*}{ No. of mvmts. } & \multirow{2}{*}{ Movement order } & \multicolumn{5}{|c|}{ Movement types } \\
\hline & & First Fast & Slow & Scherzo & Finale & Unconventional \\
\hline \multirow{4}{*}{3} & 1 & 23 & & & & \\
\hline & 2 & & 19 & 3 & & 1 \\
\hline & 3 & & & 1 & 22 & \\
\hline & (subtotals) & 23 & 19 & 4 & 22 & 1 \\
\hline \multirow{5}{*}{4} & 1 & 210 & & & & 1 \\
\hline & 2 & 1 & 152 & 59 & & \\
\hline & 3 & & 58 & 153 & & 1 \\
\hline & 4 & & & & 212 & \\
\hline & (subtotals) & 211 & 210 & 212 & 212 & 2 \\
\hline \multirow{6}{*}{5} & 1 & 10 & & & & \\
\hline & 2 & & 4 & 6 & & \\
\hline & 3 & & 5 & 5 & & \\
\hline & 4 & & 4 & 3 & & 3 \\
\hline & 5 & & & & 10 & \\
\hline & (subtotals) & 10 & 13 & 14 & 10 & 3 \\
\hline
\end{tabular}

\section{Movement Keys}

Since Horton's study already provides detailed information about inter-movement key relationships for nineteenth-century symphonies (2013, pp. 251-264), my comments on movement keys largely serve to confirm his findings by analyzing a larger corpus and by presenting the results in a different format. Table 3 and Table 4 count the number of movements for each movement type, organized into rows by movement key, expressed as Roman numerals relative to the key of the entire symphony. Table 3 includes movements in major keys, and Table 4 includes movements in minor keys. For symphonies without a key specified in the title, I take the first movement's key to be the overall key.

First movements and finales are practically always in the home key of the entire cycle, but a few comments on these movements are nevertheless in order. Although composers generally use the modality of the beginning of the first movement when giving a title to a symphony, occasionally the first movement will begin with the other modality. Beginning a major-key symphony in the parallel minor is slightly more common (5 movements) than beginning a minor-key symphony in the parallel major (2 movements). This tendency to move from minor to major across the symphonic cycle is even more pronounced in symphonies 
titled with the modality of the first movement (or without a modality in the title): 38 minor-key symphonies have finales in the major mode, compared to just 11 major-key symphonies with finales in the minor mode. Symphonies in minor keys may also be more likely to have a finale in a key with a completely different tonic: of the 144 finales from major-key symphonies, only two are in completely different keys than the first movement, but of the 103 finales from minor-key symphonies, four are in foreign keys.

For slow movements, the subdominant is the most common key in major-key symphonies, followed by the submediant. In minor-key symphonies, however, the subdominant is a less common choice for the slow movement - the submediant is the default choice, followed by the mediant. In both major- and minor-key symphonies, scherzos are most commonly in the home key of the entire cycle, with the submediant the second most common choice.

Every chromatic scale degree has at least one example of a movement in that key. For minor-key symphonies, all chromatic scale degrees are present. Major-key symphonies have inner movements in keys with all tonics except for one: no major-key symphony has an inner movement whose tonic lies a tritone away from the home key's tonic.

Table 3. Movement keys in major-key symphonies

\begin{tabular}{|c|c|c|c|c|c|c|c|}
\hline \multirow{2}{*}{$\begin{array}{c}\text { Scale-degree } \\
\text { categories }\end{array}$} & \multirow{2}{*}{$\begin{array}{l}\text { Chromatic } \\
\text { details of keys }\end{array}$} & \multicolumn{6}{|c|}{ Movement types } \\
\hline & & $\begin{array}{l}\text { First } \\
\text { Fast }\end{array}$ & Slow & Scherzo & Finale & Only & Unconventional \\
\hline \multirow{3}{*}{$\mathbf{I}$} & $i^{b^{3}}$ & 5 & 12 & 11 & 12 & & 1 \\
\hline & I & 141 & 4 & 61 & 130 & 17 & 3 \\
\hline & (subtotal) & 146 & 16 & 72 & 142 & 17 & 4 \\
\hline \multirow{4}{*}{ II } & b II & & 2 & & & & \\
\hline & ii & & & 1 & & & 1 \\
\hline & $\mathbf{I I}^{\sharp 3}$ & & 1 & & 1 & & \\
\hline & (subtotal) & & 3 & 1 & 1 & & 1 \\
\hline \multirow{5}{*}{ III } & $b$ iii $^{b 3}$ & & & & 1 & & \\
\hline & b III & & 6 & 5 & & & \\
\hline & iii & & 8 & 8 & & & 1 \\
\hline & III $^{\# 3}$ & & 7 & 1 & & & 1 \\
\hline & (subtotal) & & 21 & 14 & 1 & & 2 \\
\hline \multirow{3}{*}{ IV } & iv $^{\text {b3 }}$ & & 8 & 4 & & & 1 \\
\hline & IV & & 41 & 10 & & & 2 \\
\hline & (subtotal) & & 49 & 14 & & & 3 \\
\hline \multirow{3}{*}{ V } & $\mathbf{V}$ & & 15 & 9 & & & \\
\hline & $\mathbf{v}^{\mathrm{b3}}$ & & 3 & 3 & & & \\
\hline & (subtotal) & & 18 & 12 & & & \\
\hline \multirow{4}{*}{ VI } & b VI & & 8 & 6 & & & \\
\hline & vi & & 21 & 13 & & & 3 \\
\hline & $\mathbf{V I}^{\ddagger 3}$ & & 4 & 4 & & & 1 \\
\hline & (subtotal) & & 33 & 23 & & & 4 \\
\hline \multirow{6}{*}{ VII } & $b$ vii $^{b 3}$ & & 1 & & & & \\
\hline & b VII & & 1 & & & & \\
\hline & vii & & 1 & & & & \\
\hline & $\mathrm{VII}^{\# 3}$ & & 2 & 1 & & & \\
\hline & (subtotal) & & 5 & 1 & & & \\
\hline & grand total & 146 & 145 & 137 & 144 & 17 & 14 \\
\hline
\end{tabular}


Table 4. Movement keys in minor-key symphonies

\begin{tabular}{|c|c|c|c|c|c|c|c|}
\hline \multirow{2}{*}{$\begin{array}{l}\text { Scale-degree } \\
\text { categories }\end{array}$} & \multirow{2}{*}{$\begin{array}{c}\text { Chromatic } \\
\text { details of keys }\end{array}$} & \multicolumn{6}{|c|}{ Movement types } \\
\hline & & $\begin{array}{c}\text { First } \\
\text { Fast }\end{array}$ & Slow & Scherzo & Finale & Only & Unconventional \\
\hline \multirow{3}{*}{$\mathbf{I}$} & $\mathbf{i}$ & 103 & 2 & 45 & 60 & 9 & 3 \\
\hline & $I^{\sharp 3}$ & 2 & 6 & 11 & 38 & & \\
\hline & (subtotal) & 105 & 8 & 56 & 98 & 9 & 3 \\
\hline \multirow{4}{*}{ II } & $b \mathbf{i i}^{\text {b3 }}$ & & 1 & & & & 1 \\
\hline & b II & & 4 & 1 & & & \\
\hline & II $^{\# 3}$ & & 2 & 1 & & & \\
\hline & (subtotal) & & 7 & 2 & & & 1 \\
\hline \multirow{4}{*}{ III } & III & 1 & 14 & 9 & 1 & 1 & \\
\hline & \#iii & & & 1 & & & \\
\hline & $\sharp$ III $^{\sharp 3}$ & & 3 & & 1 & & \\
\hline & (subtotal) & 1 & 17 & 10 & 2 & 1 & \\
\hline \multirow{3}{*}{ IV } & iv & & 2 & 5 & & & \\
\hline & $\mathbf{I V}^{\sharp 3}$ & & 8 & 5 & 1 & & \\
\hline & (subtotal) & & 10 & 10 & 1 & & \\
\hline \multirow{4}{*}{$\mathbf{V}$} & b $\mathbf{V}$ & & & 1 & & & 1 \\
\hline & $\mathbf{v}$ & & 5 & 1 & & & \\
\hline & $\mathbf{V}^{\sharp 3}$ & & 8 & 5 & 2 & & \\
\hline & (subtotal) & & 13 & 7 & 2 & & 1 \\
\hline \multirow{5}{*}{ VI } & $\mathbf{v i}^{\text {b3 }}$ & 1 & 3 & & & & \\
\hline & VI & & 40 & 9 & & & \\
\hline & $\# \mathbf{v i}$ & & 1 & 2 & & & 1 \\
\hline & $\# \mathbf{V I} \mathbf{I}^{\# 3}$ & & 1 & 2 & & & \\
\hline & (subtotal) & 1 & 45 & 13 & & & 1 \\
\hline \multirow{4}{*}{ VII } & Vii $^{\text {b3 }}$ & & & 1 & & & \\
\hline & VII & & 4 & 1 & & & \\
\hline & $\# V_{I I}^{\# 3}$ & & 1 & & & & \\
\hline & (subtotal) & & 5 & 2 & & & \\
\hline \multicolumn{2}{|l|}{ Grand total } & 107 & 105 & 100 & 103 & 10 & 6 \\
\hline
\end{tabular}

\section{Prevalence of Sonata Form}

The first movements of most symphonies are, of course, examples of sonata form, whereas the forms of other movement types are more variable. If a movement is not a clear example of sonata form, I do not analyze its internal structure in any detail. Within the corpus, we can define precisely how often sonata form occurs in each type of movement: 74\% of single-movement symphonies, 93\% of first fast movements, $22 \%$ of slow movements, $6 \%$ of scherzos,[3] $63 \%$ of finales, and $5 \%$ of other, unconventional movement types make clear use of sonata form.

These values vary over time: Table 5 breaks them down by decade, and the line chart in Figure 2 illustrates the data for the three movement types that account for most of the sonata forms in the corpus: first movements, slow movements, and finales. In first movements, sonata form becomes slightly less common later in the century, ranging above $95 \%$ in the 1800 s to 1830 s, but between $85 \%$ and $95 \%$ from the 1840s onwards. This modest decline likely results from composers' explorations of alternative designs, especially program symphonies, which do not always use sonata form. The rate nevertheless remains very high: even toward the end of the century, close to $90 \%$ of first movements are sonatas. The forms of slow movements and finales are more variable, but in finales the occurrence of sonata form does seem in general 
to trend slightly upwards, especially before 1850 . This trend likely results from a move away from rondos or sonata-rondos toward more finales in purer sonata form.

Table 5. Prevalence of sonata form different movement types

\begin{tabular}{|c|c|c|c|c|c|c|c|c|c|c|c|c|}
\hline & & $1800 \mathrm{~s}$ & $1810 \mathrm{~s}$ & $1820 \mathrm{~s}$ & $1830 \mathrm{~s}$ & $1840 \mathrm{~s}$ & $1850 \mathrm{~s}$ & $1860 \mathrm{~s}$ & $1870 \mathrm{~s}$ & $1880 \mathrm{~s}$ & $1890 \mathrm{~s}$ & Total \\
\hline \multirow{3}{*}{ First Fast } & \multirow{3}{*}{$\begin{array}{l}\text { sonatas } \\
\text { total }\end{array}$} & 26 & 21 & 13 & 23 & 13 & 20 & 17 & 26 & 36 & 41 & 236 \\
\hline & & 27 & 22 & 13 & 24 & 14 & 21 & 19 & 30 & 38 & 45 & 253 \\
\hline & & $96 \%$ & $95 \%$ & $100 \%$ & $96 \%$ & $93 \%$ & $95 \%$ & $89 \%$ & $87 \%$ & $95 \%$ & $91 \%$ & $93 \%$ \\
\hline \multirow{3}{*}{ Slow } & \multirow{3}{*}{$\begin{array}{l}\text { sonatas } \\
\text { total }\end{array}$} & 7 & 3 & 5 & 8 & 4 & 3 & 7 & 5 & 9 & 5 & 56 \\
\hline & & 26 & 23 & 13 & 25 & 13 & 21 & 19 & 29 & 39 & 42 & 250 \\
\hline & & $27 \%$ & $13 \%$ & $38 \%$ & $32 \%$ & $31 \%$ & $14 \%$ & $37 \%$ & $17 \%$ & $23 \%$ & $12 \%$ & $22 \%$ \\
\hline \multirow{3}{*}{ Scherzo } & \multirow{3}{*}{$\begin{array}{l}\text { sonatas } \\
\text { total }\end{array}$} & 0 & 0 & 0 & 2 & 4 & 0 & 2 & 1 & 1 & 4 & 14 \\
\hline & & 24 & 20 & 13 & 24 & 11 & 19 & 20 & 28 & 35 & 43 & 237 \\
\hline & & $0 \%$ & $0 \%$ & $0 \%$ & $8 \%$ & $36 \%$ & $0 \%$ & $10 \%$ & $4 \%$ & $3 \%$ & $9 \%$ & $6 \%$ \\
\hline \multirow{3}{*}{ Finale } & \multirow{3}{*}{$\begin{array}{l}\text { sonatas } \\
\text { total }\end{array}$} & 14 & 13 & 8 & 13 & 10 & 10 & 16 & 19 & 26 & 27 & 156 \\
\hline & & 26 & 22 & 12 & 22 & 14 & 20 & 19 & 30 & 37 & 45 & 247 \\
\hline & & $54 \%$ & $59 \%$ & $67 \%$ & $59 \%$ & 71\% & $50 \%$ & $84 \%$ & $63 \%$ & $70 \%$ & $60 \%$ & $63 \%$ \\
\hline \multirow{3}{*}{ Only } & \multirow{3}{*}{$\begin{array}{l}\text { sonatas } \\
\text { total }\end{array}$} & 5 & 5 & 3 & 7 & 0 & 0 & 0 & 0 & 0 & 0 & 20 \\
\hline & & 7 & 8 & 4 & 8 & 0 & 0 & 0 & 0 & 0 & 0 & 27 \\
\hline & & $71 \%$ & $63 \%$ & $75 \%$ & $88 \%$ & N/A & N/A & N/A & N/A & N/A & N/A & $74 \%$ \\
\hline \multirow{3}{*}{\multicolumn{2}{|c|}{$\begin{array}{l}\text { sonatas } \\
\text { Unconventional total }\end{array}$}} & 0 & 0 & 0 & 0 & 0 & 0 & 1 & 0 & 0 & 0 & 1 \\
\hline & & 1 & 0 & 0 & 2 & 8 & 3 & 1 & 1 & 0 & 4 & 20 \\
\hline & & $0 \%$ & N/A & N/A & $0 \%$ & $0 \%$ & $0 \%$ & $100 \%$ & $0 \%$ & N/A & $0 \%$ & $5 \%$ \\
\hline
\end{tabular}

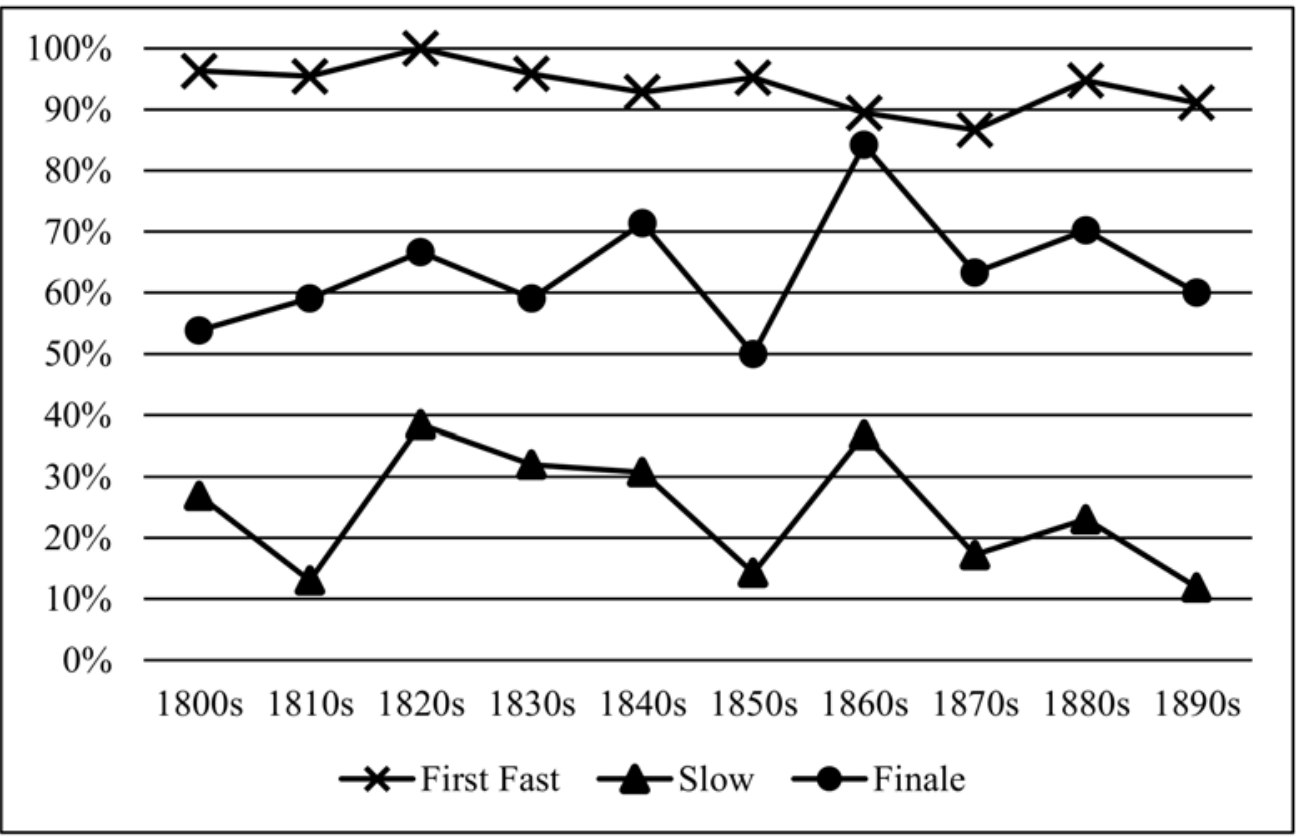

Fig. 2. Prevalence of sonata form in first movements, slow movements, and finales.

\section{SONATA-FORM MOVEMENTS}

In discussing symphonic sonata-form movements, I now deal with six easily identified features. First, knowing the measure numbers of important formal events in each movement allows one to make general 
statements of the proportions of sonata form in this genre. Second, the decline in popularity of expositional repeats is evident in the corpus. Third, the tonal trajectory of expositions is quite standard in this repertoire, but exceptions in this regard are noteworthy. Fourth, recapitulations often return to points in the exposition other than the start of the main theme. Fifth, recapitulations sometimes begin in foreign keys. And sixth, some movements end in different keys than where they began.

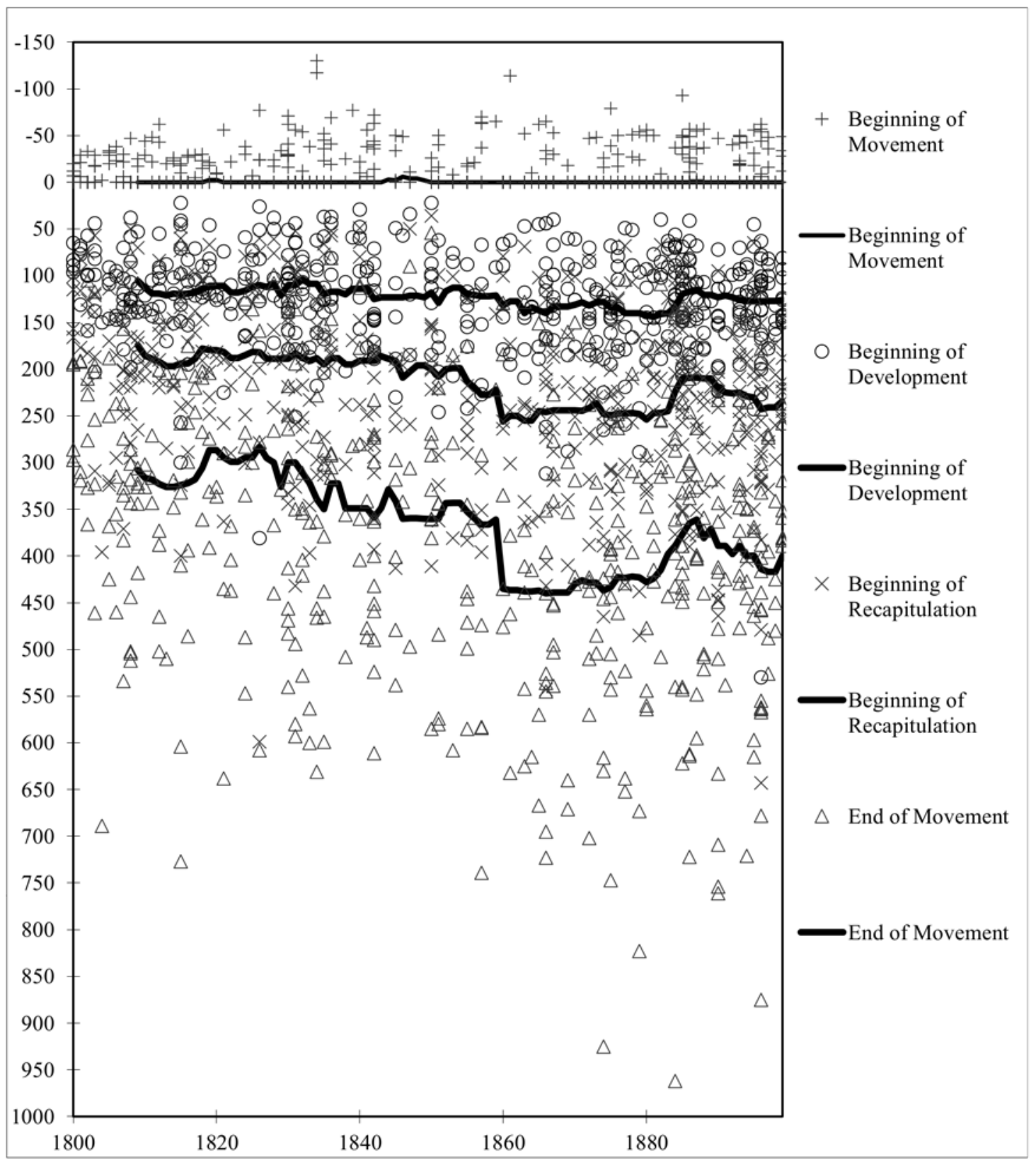

Fig. 3. Locations of Major Formal Boundaries in Sonata Form, as Measure Numbers, with Onset of Exposition set to Zero, and 10-Year Moving Medians. 


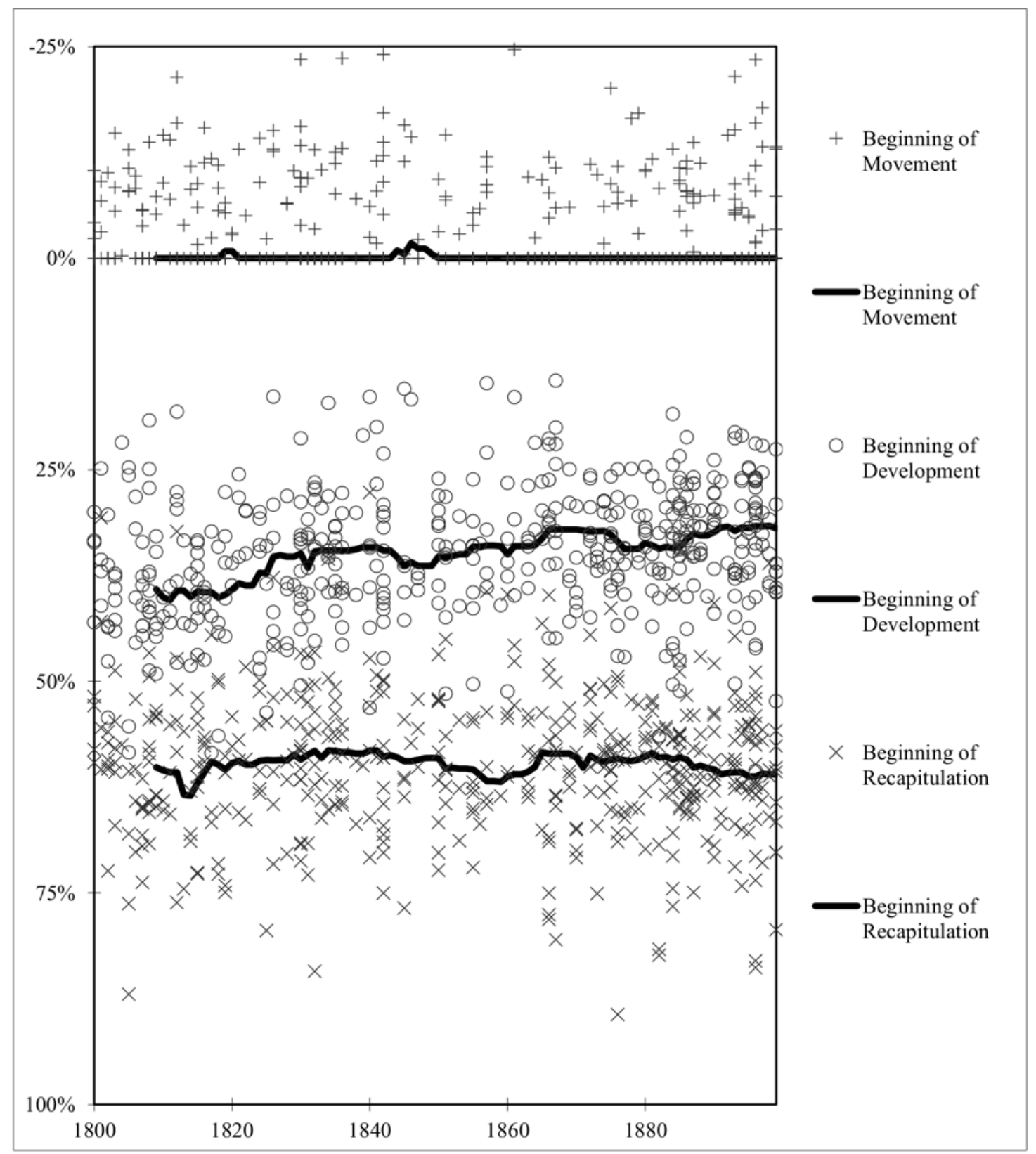

Fig. 4. Locations of Major Formal Boundaries as Percentages with the Onset of Exposition set to Zero and the End of the Movement set to 100, and with 10-Year Moving Medians.

\section{Proportions of Sonata Form}

Since the survey data include the lengths of movements and the locations of important formal divisions, they can show the general proportions of sonata form in the nineteenth-century symphony. Figure 3 shows the locations, in measure numbers, of four major formal boundaries in sonata form: the beginnings of the entire movement, the exposition, the development, and the recapitulation, as well as the end of the movement. The vertical axis measures musical time in measure numbers downward, and the horizontal axis measures historical time in years from left to right. To avoid clutter at the top of the chart, I subtract the length of the introduction from all values; this subtraction makes the beginning of the exposition zero in all cases, with the beginning of the slow introduction, if present, becoming a negative number. Since the beginning of the exposition is zero in all cases, I omit markers for this point in the form. The adjusted 
measure number of the formal boundaries in each sonata-form movement in the corpus appears on the chart as a point in the scatter plot: a "+" for the beginning of the movement, a circle for the beginning of the development section, an " $x$ " for the beginning of the recapitulation, and a triangle for the end of the movement. To show possible patterns, I add a trend line for each formal boundary as a moving median of the previous ten years.

Most values increase early in the century before levelling off sometime around 1865 . Beginning at the bottom of the chart with the ends of movements, total movement length (minus slow introductions) shows the greatest increase, starting out at around 300-325 measures in 1800-1830 and ending up at around 400-475 after 1865-a growth of about 30\%. The median distance from the beginning of the exposition to the beginning of the recapitulation also increases, from about 190 measures to about 240 measures. The location of the onset of the development (again, minus the slow introduction) indicates the length of the exposition, which only shows a slight increase, beginning at around 110 measures and ending up at around 130, a growth of about $15 \%$. Since the majority of movements (62\% of all sonata forms in the corpus) have no slow introduction, the median for the beginning of the movement usually stays at zero.

To compensate for the wide variety of movement lengths, Figure 4 displays the same information as Figure 3, but with the distance between the beginning of the exposition and the end of the movement set to $100 \%$. Again, each point in the scatter plot represents the location of a formal boundary in an individual work, but this time expressed as a percentage of total movement length, minus the slow introduction if present. This chart omits the points for the ends of movements because they form the bottom border of the chart at $100 \%$. Working from the top down this time, the space devoted to introductions becomes larger relative to the rest of the chart. This apparent enlargement results from the adjustment to percentages: since the end of each movement is at $100 \%$, the outliers in terms of total movement length no longer require extra space at the bottom of the chart. The median location of the onset of development becomes earlier in musical time over the years - in other words, expositions become a smaller percentage of total movement length later in the century. The line for the beginning of the recapitulation, however, remains fairly level at around $60 \%$.

Figure 5 shows the main pattern more clearly by directly comparing the proportional lengths of the exposition and development sections. The relative expansion of the development at the expense of the exposition is evident in the 10-year moving median trend lines. The vertical axis in this chart does not track musical time, but instead measures the length of the exposition and development sections as percentages of the total movement length (now including the slow introduction, if present). In the first half of the century, the length of a typical exposition gradually drops from about $38 \%$ to $35 \%$ of total movement length; then, in the second half of the century, it fluctuates between $31 \%$ and $35 \%$. A corresponding increase in the relative length of development sections accounts for much of this change: before the 1840s, the development typically takes up only about $20 \%$ of the movement's total length, but after the 1860 s this proportion is closer to $25 \%$.

\section{Expositional Repeats}

In the high Classical style of the late eighteenth century, the exposition of a sonata frequently ends with a repeat sign. In later styles, however, the repeat becomes rare. Table 6 and Figure 6 illustrate this shift in design. The exposition repeats in a majority of sonata-form movements before 1840, but in very few movements later in the century. After 1860 , only around $20 \%$ of the movements have a repeat sign at the end of the exposition. 


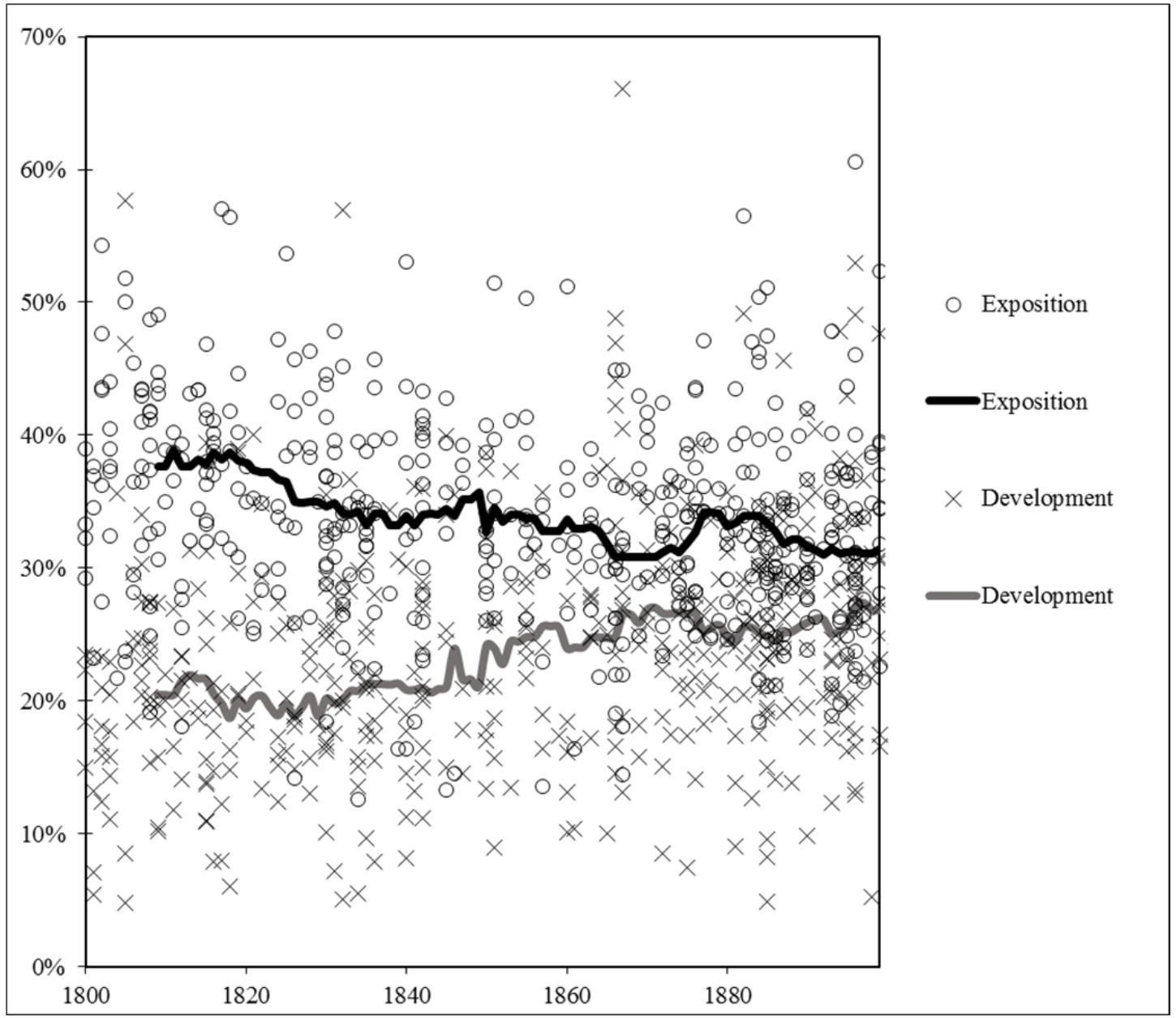

Fig. 5. Lengths of Expositions and Developments as Proportions of Total Movement Length, by Year with 10-Year Moving Medians

Table 6. Numbers of sonata-form movements per decade with and without expositional repeat

\begin{tabular}{|l|c|c|c|c|c|c|c|c|c|c|}
\cline { 2 - 11 } \multicolumn{1}{c|}{} & 1800 s & 1810 s & 1820 s & 1830 s & $1840 s$ & $1850 s$ & $1860 s$ & $1870 s$ & $1880 s$ & $1890 s$ \\
\hline Repeat & 29 & 29 & 16 & 28 & 11 & 16 & 9 & 12 & 11 & 16 \\
\hline No Repeat & 23 & 13 & 13 & 25 & 20 & 17 & 34 & 39 & 61 & 61 \\
\hline
\end{tabular}

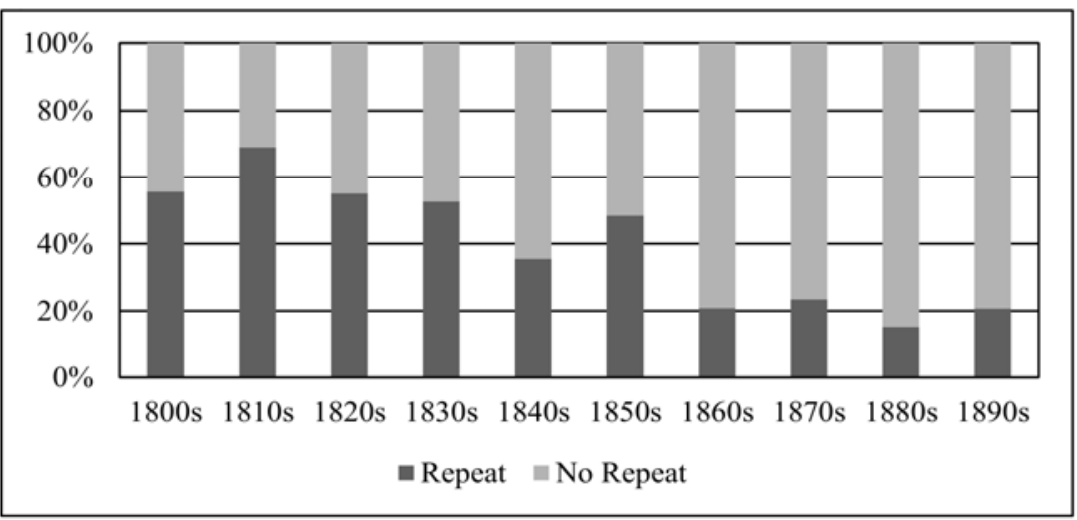

Fig. 6. Percentages of sonata-form movements per decade with and without expositional repeat 


\section{Last Key of Exposition}

Horton (2013, p. 237) observes that the standard keys for subordinate themes (dominant for sonatas in major keys and mediant for those in minor keys) remain common in symphonies throughout the nineteenth century (in contrast to more adventurous tonal designs in chamber and vocal works), and gives an account of the occasional alternative choices. His analysis, however, only deals with selected prominent works from the repertoire- that is, he does not deal with the internal structure of movements in his corpus study. My corpus study supports Horton's more qualitative findings. Bear in mind that my analysis only examines the very ends of expositions. Many of these movements may feature three-key expositions, initially presenting their subordinate themes in different keys before modulating to the keys given in the tables below, but I do not account for such details in the middles of expositions. In major-key movements (Table 7), the dominant is the most common destination key for the exposition, followed by the mediant. The reverse is true for minor-key movements (Table 8): the mediant is most common followed by the dominant. The third most common choice is the submediant for movements in both major and minor keys.

Table 7. Last key in exposition in major-key sonata-form movements

\begin{tabular}{|c|c|c|c|c|c|c|c|c|c|c|c|c|}
\hline $\begin{array}{l}\text { Scale-degree } \\
\text { categories }\end{array}$ & $\begin{array}{c}\text { Chromatic } \\
\text { details of keys }\end{array}$ & ஜ̊̊̊ & $\underset{\infty}{\infty}$ & 帘 & ஜ્ & 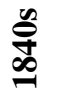 & 号 & ஜ્ષ & 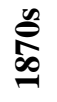 & ஜ & ஜ̊̊ & 预 \\
\hline \multirow{2}{*}{ I } & $i^{b 3}$ & & & & 1 & & & & & 1 & & 2 \\
\hline & (subtotal) & & & & 1 & & & & & 1 & & 2 \\
\hline \multirow{4}{*}{ II } & b II & & & & & & & & 1 & & & 1 \\
\hline & ii & & & & & & & 1 & & & & 1 \\
\hline & II $^{\# 3}$ & & & & & & & & & 1 & & 1 \\
\hline & (subtotal) & & & & & & & 1 & 1 & 1 & & 3 \\
\hline \multirow{5}{*}{ III } & $b$ iii $^{b 3}$ & & & & & & & & & 1 & & 1 \\
\hline & b III & & & & 1 & & & & 1 & 1 & 1 & 4 \\
\hline & iii & & & & & & & & 2 & 1 & 4 & 7 \\
\hline & III $^{\sharp 3}$ & & 1 & 1 & 1 & & & & 2 & 4 & 6 & 15 \\
\hline & (subtotal) & & 1 & 1 & 2 & & & & 5 & 7 & 11 & 27 \\
\hline \multirow{3}{*}{ IV } & IV & & & & & & & 1 & & & 1 & 2 \\
\hline & $\#$ iv & & & & & & 1 & & & & & 1 \\
\hline & (subtotal) & & & & & & 1 & 1 & & & 1 & 3 \\
\hline \multirow{3}{*}{$\mathbf{V}$} & $\mathbf{v}^{b^{3}}$ & & & & 1 & & & & & & 2 & 3 \\
\hline & $\mathbf{V}$ & 43 & 34 & 17 & 24 & 18 & 20 & 24 & 24 & 29 & 23 & 256 \\
\hline & (subtotal) & 43 & 34 & 17 & 25 & 18 & 20 & 24 & 24 & 29 & 25 & 259 \\
\hline \multirow{4}{*}{ VI } & b VI & & & & & & & & 2 & 3 & 1 & 6 \\
\hline & vi & 1 & & & & & & 1 & & 2 & 1 & 5 \\
\hline & $\mathrm{VI}^{\sharp 3}$ & & & & & & 1 & 1 & & 3 & & 5 \\
\hline & (subtotal) & 1 & & & & & 1 & 2 & 2 & 8 & 2 & 16 \\
\hline \multirow{4}{*}{ VII } & b VII & & & 1 & & & & & & & & 1 \\
\hline & vii & & & & & & & & & 1 & & 1 \\
\hline & $\mathrm{VII}^{\# 3}$ & & & & & & & & & & 1 & 1 \\
\hline & (subtotal) & & & 1 & & & & & & 1 & 1 & 3 \\
\hline
\end{tabular}


Table 8. Last key in exposition in minor-key sonata-form movements

\begin{tabular}{|c|c|c|c|c|c|c|c|c|c|c|c|c|}
\hline $\begin{array}{l}\text { Scale-degree } \\
\text { categories }\end{array}$ & $\begin{array}{l}\text { Chromatic } \\
\text { details of keys }\end{array}$ & 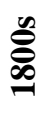 & $\underset{\infty}{\infty}$ & ڤ્ડે & ஜ્ڤ & $\underset{\infty}{\stackrel{0}{+}}$ & $\begin{array}{l}\infty \\
\text { 옹 } \\
\stackrel{\infty}{=}\end{array}$ & $\begin{array}{l}\infty \\
\mathscr{0} \\
\infty\end{array}$ & $\underset{\substack{\infty \\
\oplus}}{\infty}$ & $\begin{array}{l}\mathscr{\infty} \\
\stackrel{\infty}{\infty} \\
\stackrel{\infty}{-1}\end{array}$ & ஜ̊ & స్ㅠㅁ \\
\hline \multirow{2}{*}{ II } & $\mathrm{II}^{\ddagger 3}$ & & & & & & & & & 1 & & 1 \\
\hline & (subtotal) & & & & & & & & & 1 & & 1 \\
\hline \multirow{4}{*}{ III } & iii $^{\text {b3 }}$ & & & & & & 1 & & & & & 1 \\
\hline & III & 5 & 5 & 8 & 20 & 10 & 5 & 12 & 9 & 12 & 20 & 106 \\
\hline & $\#$ IIII $^{\# 3}$ & & & & & & 1 & & & & & 1 \\
\hline & (subtotal) & 5 & 5 & 8 & 20 & 10 & 7 & 12 & 9 & 12 & 20 & $\overline{108}$ \\
\hline \multirow{2}{*}{ IV } & $I^{\sharp 3}$ & & & & & & & & & & & 1 \\
\hline & (subtotal) & & & & & & & & 1 & & & 1 \\
\hline \multirow{4}{*}{ V } & $b \mathbf{V}$ & & & & & & & & 1 & 1 & & 2 \\
\hline & $\mathbf{v}$ & 2 & & & 4 & 2 & & 1 & 1 & 5 & 5 & 20 \\
\hline & $\mathbf{V}^{\sharp 3}$ & 1 & 1 & & & 1 & 1 & 1 & 4 & 3 & 2 & 14 \\
\hline & (subtotal) & 3 & 1 & & 4 & 3 & 1 & 2 & 6 & 9 & 7 & 36 \\
\hline \multirow{3}{*}{ VI } & $\mathbf{v i}^{\text {b3 }}$ & & & & & & & & & & 1 & 1 \\
\hline & VI & & 1 & 2 & 1 & & 2 & 1 & 3 & 2 & 6 & 18 \\
\hline & (subtotal) & & 1 & 2 & 1 & & 2 & 1 & 3 & 2 & 7 & 19 \\
\hline \multirow{3}{*}{ VII } & VII & & & & & & 1 & & & 1 & 2 & 4 \\
\hline & $\# \mathrm{VII}^{\# 3}$ & & & & & & & & & & 1 & 1 \\
\hline & (subtotal) & & & & & & 1 & & & 1 & 3 & 5 \\
\hline
\end{tabular}

Regarding alternative, fourth-level choices for the end of the exposition, composers treat majorkey movements rather differently than minor-key ones. In major-key movements, composers prefer significant levels of chromaticism. The major mediant $\left(\mathrm{III}^{\sharp 3}\right)$ is much more common than the minor mediant (iii). Fifteen movements make use of the major mediant while only seven use the minor mediant. Four additional movements use the flattened mediant ( $b$ III). The flat submediant ( $b$ VI) is slightly more common than the diatonic minor submediant (that is, the relative minor: vi). Six movements use the flat submediant while five use the relative minor. Five movements also use a submediant altered to be in the major mode $\left(\mathrm{VI}^{\sharp 3}\right)$. In minor-key movements, by contrast, composers prefer to end the exposition in more diatonic keys. The minor dominant $(\mathrm{v})$ is more common than the major dominant $\left(\mathrm{V}^{\sharp 3}\right)$. Twenty minor-key movements end their expositions in the key of the minor dominant, compared to fourteen movements that do so in the major dominant. The major submediant (VI) is more common than the minor submediant ( $\mathrm{vi}^{\text {b }}$ ${ }^{3}$ ). Eighteen movements end the exposition in the major submediant, but only one does so in the minor submediant.

Alternative keys become more common later in the century, especially for movements in major keys. Figure 7 shows the percentage of major-key movements in each decade that end the exposition in the key of the dominant (the default choice). In the first half of the century this proportion remains above 85\%, but starting in the 1850s it steadily declines, dropping below $60 \%$ by the 1890 s. The trend for the default subordinate key in minor-key movements, shown in Figure 8, is less clear. The mediant is more common in the first half of the century than in the second half, but the values fluctuate significantly from decade to decade. 


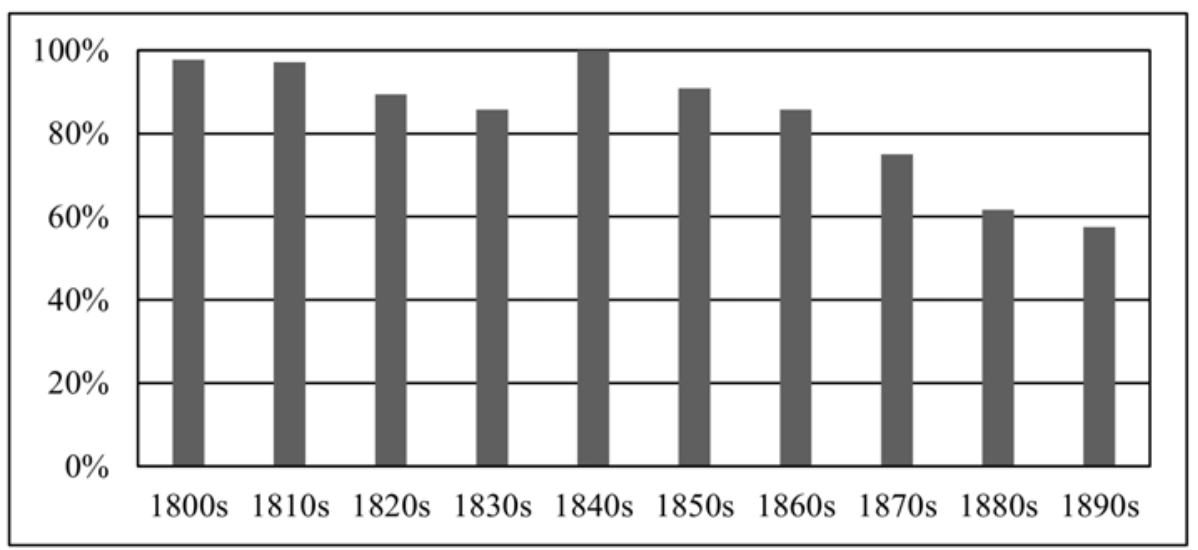

Fig. 7. Percentages of major-key movements in each decade with expositions ending in the key of the dominant.

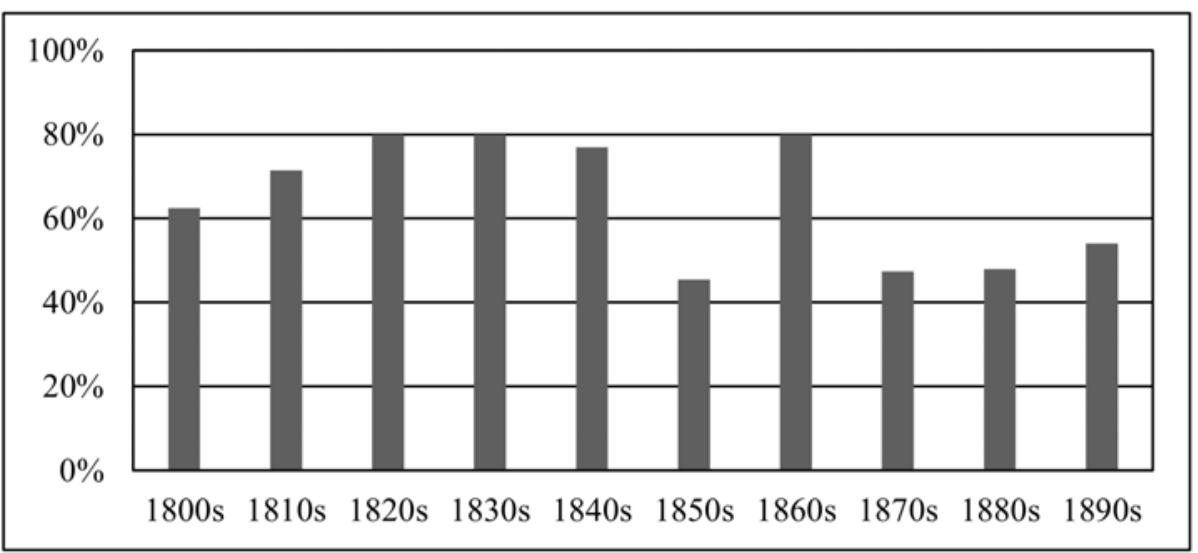

Fig. 8. Percentages of minor-key movements in each decade with expositions ending in the key of the mediant.

The rarer alternative key choices for ending expositions deserve further comment. Keys based on every category of scale degree are present in the corpus. For major-key movements, every chromatic scale degree becomes the goal key of the exposition in at least one movement. The inclusion of two major-key movements with subordinate themes in the parallel minor may raise some eyebrows. Analysts who consider the cadential confirmation of a contrasting subordinate key essential to sonata form may wish to analyze these movements as A-B-A ternary forms instead.[4] Among minor-key movements, the only chromatic scale steps that never form the goal key of an exposition are b II and \#VI. Most of the rarer keys occur only once or twice in the corpus, although ending the exposition with the major subtonic is slightly more common, occurring in four minor-key movements.

\section{Points of Return}

Table 9 counts the sonata-form movements in the corpus by which part of the exposition corresponds to the beginning of the recapitulation. Only 7 movements ( $1.4 \%$ of the total) return to a point earlier than the beginning of the main theme (that is, to a point during the slow introduction). The vast majority of movements (391, or $81 \%$ - the total of the second and third rows in Table 9) return to the beginning of the main theme. Of these 391 movements that return to the beginning of the main theme, 73 omit some portion of the initial material that sometimes precedes the strong entrance of the main theme proper. After the beginning of the main theme, the numbers of movements that return to later points in the recapitulation decrease at a remarkably steady rate: 37 movements (7.7\%) return to some point after the beginning of the main theme but before the transition, 22 movements (4.6\%) return to the beginning of the transition, 12 
(2.5\%) return to some point within the transition, $8(1.7 \%)$ return to the beginning of the subordinate theme, and $3(0.6 \%)$ return to some point within the subordinate theme group.

Given the variety of points to which the recapitulation might return, drawing a line between a "Type 2" and "Type 3" sonata is impossible. On the one hand, many transitions use melodic material from the main theme, such that even a movement whose recapitulation completely skips the main theme may still be understood as Type 3. On the other hand, if an expositional main theme features a prominent head motif or motto that is absent in the recapitulation, one might hear aspects of Type 2 even if the recapitulation includes the end of the main theme-in such a case, there would be no obvious moment of return, with the retransition blurring into the recapitulation of the main theme. Movements that fall unequivocally into the Type 2 category can only be those that include no return of any material from the main theme or transition; such movements are rare in the symphonic repertoire.

Three movements in the corpus do not obviously include measure-by-measure correspondence between the exposition and the onset of recapitulation: the first movements of Francisco Moreno's third symphony (1805), Hector Berlioz's Symphonie fantastique (1830), and Mily Balakirev's first symphony (1866). Despite this lack of correspondence, I analyze these movements as sonata forms with highly altered recapitulations because each of them features an extended section in the home key after the development. Another analyst, however, might not choose not to classify these movements as sonata forms.

Table 9. Number of sonata-form movements with recapitulations beginning at various expositional points

\begin{tabular}{|l|l|}
\hline Points from exposition to which the onset of recapitulation corresponds & Count \\
\hline Slow introduction & 7 \\
\hline Beginning of main theme & 318 \\
\hline Beginning of main theme, initial material omitted & 73 \\
\hline Between beginning of main theme and transition & 37 \\
\hline Beginning of transition & 22 \\
\hline Between beginning of transition and subordinate theme & 12 \\
\hline Beginning of subordinate theme & 8 \\
\hline After beginning of subordinate theme & 3 \\
\hline No clear correspondence & 3 \\
\hline
\end{tabular}

\section{Recapitulations in Foreign Keys or with Altered Initial Harmony}

Table 10 categorizes the various ways that keys or harmonies differ between the beginning of the exposition and the beginning of the recapitulation, giving counts of the numbers of movements that involve each situation. The table only includes the 318 movements whose recapitulations begin with the start of the main theme, without omitting any initial material. I consider harmonies to be equivalent if they can be analyzed with the same Roman numeral and figured bass symbols - that is, if they have the same pitch class content, with the same chord member in the lowest sounding voice. The majority of movements (241, or $75.8 \%$ ) have the same harmony at the beginning of the recapitulation as at the beginning of the exposition. I organize the alterations in order of structural depth, from deeper to more superficial: first foreign keys, then parallel keys, then the same key but harmonies with different roots, then the same harmony in the same key but in different inversion, and finally the addition of a dissonant seventh.

Nine movements return to the home key, but in the parallel mode. Most of these changes of mode involve switching from tonic minor in the exposition to tonic major in the recapitulation, with seven examples in the corpus. Only 2 movements feature a major-key main theme that begins in the parallel minor for the recapitulation: the first movement of Spohr's seventh symphony (1842) and the first movement of Ernest Chausson's Symphony in B b major, Op. 20 (1890). Nineteen movements return to the home key, but begin the main theme with a harmony different from the exposition. These harmonic alterations may amount to a re-harmonization of the same melody (for example, melodies that start with scale-degree 5 can easily begin over either tonic or dominant harmony), or may accommodate more significant changes to the melody. The most common types of change involve switching a dominant to a tonic (8 movements) or vice versa (4 movements). 
Table 10. Number of sonata-form movements with recapitulations beginning in foreign keys or with altered harmony

\begin{tabular}{|l|l|}
\hline Change to key or harmony at onset of recapitulation & Count \\
\hline No Change & 241 \\
\hline Foreign Key: Subdominant & 4 \\
\hline Foreign Key: Mediant & 3 \\
\hline Foreign Key: Submediant & 2 \\
\hline Foreign Key: Dominant & 2 \\
\hline Foreign Key: Supertonic & 1 \\
\hline Foreign Key: Subtonic & 1 \\
\hline Mode Change: Tonic Major instead of Minor & 7 \\
\hline Mode Change: Tonic Minor instead of Major & 2 \\
\hline Different Root: Tonic instead of Dominant & 8 \\
\hline Different Root: Dominant instead of Tonic & 4 \\
\hline Different Root: Supertonic instead of Tonic & 2 \\
\hline Different Root: Leading Tone instead of Tonic & 1 \\
\hline Different Root: Mediant instead of Dominant & 1 \\
\hline Different Root: Subtonic instead of Subdominant & 1 \\
\hline Different Root: Submediant instead of Tonic & 1 \\
\hline Different Root: Tonic instead of Submediant & 1 \\
\hline Different Inversion: Second Inversion Tonic instead of Root Position & 20 \\
\hline Different Inversion: First Inversion Tonic instead of Root Position & 8 \\
\hline Different Inversion: Root Position Tonic instead of First Inversion & 3 \\
\hline Different Inversion: Root Position Tonic instead of Second Inversion & 1 \\
\hline Different Inversion: Second Inversion Dominant instead of Root Position & 1 \\
\hline Dissonance Added: V7 of IV instead of I & 2 \\
\hline Dissonance Added: V7 instead of V & 1 \\
\hline
\end{tabular}

Changes to the inversion of the first chord of the main theme usually serve to destabilize the initial tonic. Most commonly (20 movements) a second-inversion tonic triad at the onset of recapitulation replaces the root-position tonic from the beginning of the exposition. Many other movements not counted here also begin the recapitulation with this $6 / 4$ chord: occasionally the $6 / 4$ begins the main theme in the exposition anyway, and the 6/4 sometimes opens recapitulations that return to some point other than the beginning of the main theme. This high incidence of the $6 / 4$ has already received comment from Horton, who describes it as "widespread in nineteenth-century symphonies," (2013, p. 243) supplying five examples. The second most common type of inversion change involves beginning the recapitulation with a first-inversion tonic triad instead of root position. While the first-inversion tonic is less dissonant and unstable than the $6 / 4$, it still lacks the certainty of a root-position tonic.

\section{Key at End of Movement}

Almost every sonata-form movement in the repertoire of nineteenth-century symphonies ends in the same key as it begins. Horton (2013, pp. 248-251) discusses the few exceptions in detail, so my comments here pertain more to changes of mode rather than to true changes of key. In the context of a full symphonic cycle, we have already observed (see Table 3 and Table 4 above) that minor-key symphonies are more likely to end with a major-key finale than major-key symphonies are to end with a minor-key finale. The same tendency occurs within individual movements. Table 11 shows the keys in which movements end, relative to the movement's main key, organized into columns by movement type. Looking at the totals for all movement types in the leftmost column, observe that 27 minor-key movements end in the parallel major, compared to just 5 major-key movements ending in the parallel minor. Ending a movement in a different key than it begins is more common in finales than in other movement types. 
Table 11. Number of sonata-form movements that end in a foreign key

\begin{tabular}{|c|c|c|c|c|c|c|c|}
\hline \multirow{2}{*}{$\begin{array}{l}\text { Key at end of } \\
\text { movement, relative } \\
\text { to opening key }\end{array}$} & \multicolumn{6}{|c|}{ Movement type } & \multirow[b]{2}{*}{ Total } \\
\hline & $\begin{array}{l}\text { First } \\
\text { Fast }\end{array}$ & Slow & Finale & Only & Scherzo & $\begin{array}{c}\text { Uncon- } \\
\text { ventional }\end{array}$ & \\
\hline no change & 227 & 53 & 138 & 16 & 14 & & 448 \\
\hline$i^{b 3}$ & 2 & 1 & 1 & 1 & & & 5 \\
\hline $\mathrm{I}^{\# 3}$ & 6 & 2 & 15 & 3 & & 1 & 27 \\
\hline $\mathrm{V}$ & & & 1 & & & & 1 \\
\hline vi & 1 & & & & & & 1 \\
\hline $\mathrm{VI}^{\sharp 3}$ & & & 1 & & & & 1 \\
\hline
\end{tabular}

\section{CONCLUSION}

In general, the results of this corpus study lend numerical support for many of our standard conceptions of the nineteenth-century symphony. More symphonies date from the beginning and end of the century than from the middle. The prototypical four-movement symphony, with the order fast-slow-scherzo-finale, is indeed most common. First movements, scherzos, and finales tend to be in the symphony's home key, while slow movements are usually in foreign keys, especially the subdominant for minor-key symphonies, or the mediant and submediant for major-key symphonies. On average, movements become longer later in the century. For movements in sonata form, expositions are less frequently repeated in symphonies from toward the end of the century. Throughout the century, composers continue to prefer the standard subordinate keys: the dominant for major-key movements, and the mediant for minor-key movements. The third choice for subordinate key is the submediant. Most recapitulations begin with the double return of the main theme's material and the home key. Both within movements, and across symphonic cycles, motion from the minor mode to the major is much more common than the reverse

Some findings of the study are perhaps less intuitively obvious. Most five-movement symphonies follow just three main patterns: fast-scherzo-slow-scherzo-finale (with one of the generic "scherzos" typically a minuet or march), fast-slow-scherzo-slow-finale (with contrasting tempos such as adagio and andante for the slow movements), and fast-slow-scherzo-unconventional-finale (the inserted fourth movement typically has a programmatic meaning, such as the storm in Beethoven's Sixth). Although all sections of sonata form become longer on average in later works, much of this increase in length results from longer development sections - expositions tend to make up a smaller proportion of total movement length in later works. Fourth-level choices for subordinate keys in sonata forms vary by modality of movement key: major-key movements are much more likely to end their expositions in a chromatically distant tonal space, whereas minor-key movements prefer more diatonic subordinate keys. And finally, among changes to harmony at the onset of recapitulation, the use of a $6 / 4$ is particularly common, destabilizing the moment of return. Whether the numerical findings appear obvious or reveal new insights, they should be of use to anyone with an interest in the symphonic repertoire or in nineteenth-century sonata form.

\section{NOTES}

[1] I stopped adding works to the corpus in 2012.

[2] Two Microsoft Excel files contain the data: one includes full symphonies and the other only has sonataform movements, with more detailed analysis of internal movement structure.

[3] This count only includes scherzos where the entire movement is a sonata. Other scherzos may include sonatas embedded within the larger A-B-A form. 
[4] The works in question are Samuel Sebastian Wesley's Symphony in C (1832), which consists of just the one movement, and the slow second movement (in B-flat major) of Vincent d'Indy's Symphony in G major, “On a French Mountain Air” (1886).

\section{REFERENCES}

Brook, B. (1986). Reference Volume: Contents of the Set and Collected Thematic Indexes. The Symphony 1720-1840: A Comprehensive Collection of Full Scores in Sixty Volumes. New York: Garland.

Brown, A. P. (2002-2012). The Symphonic Repertoire (Vols 1-5). Bloomington: Indiana University Press.

Cannon, S. (2015a). "Arrival or Relaunch? Dynamics, Orchestration, and the Function of Recapitulation in the Nineteenth-Century Symphony." Poster presented at the Society for Music Theory Annual Meeting. St. Louis, Missouri, October 30, 2015.

Cannon, S. (2015b). "Altered Dynamics and Instrumentation at the Onset of Recapitulation in the Nineteenth-Century Symphony." Analitica: Rivista online di studi musicali, 8. Retrieved from http://www.gatm.it/analiticaojs/index.php/analitica/article/view/141/124

Caplin, W. (1998). Classical Form: A Theory of Formal Functions for the Instrumental Music of Haydn, Mozart, and Beethoven. New York: Oxford University Press.

Dahlhaus, C. (1978). "Liszts Idee des Symphonichen." Liszt Studies, 3, 36-42.

Dahlhaus, C. (1989). Nineteenth-Century Music. (J. B. Robinson, Trans.). Berkeley: University of California Press.

Fifield, C. (2015). The German Symphony Between Beethoven and Brahms: The Fall and Rise of a Genre. Farnham, UK: Ashgate.

Grotjahn, R. (1998). Die Sinfonie im deutschen Kulturgebiet 1850 bis 1875: ein Betrag zur Gattungs- und Institutionengeschichte. Sinzig: Studio.

Hepokoski, J., \& Darcy, W. (2006). Elements of Sonata Theory: Norms, Types, and Deformations in the Late Eighteenth-Century Sonata. New York: Oxford University Press.

https://doi.org/10.1093/acprof:oso/9780195146400.001.0001

Hofmeister, Friedrich. (2008, September 22). Hofmeister XIX. Retrieved September 14, 2015. Retrieved from http://www.hofmeister.rhul.ac.uk/2008/index.html.

Horton, J. (2013). "Tonal Strategies in the Nineteenth-Century Symphony." In J. Horton (Ed.), The Cambridge Companion to the Symphony (pp. 232-267). Cambridge: Cambridge University Press. https://doi.org/10.1017/CCO9781139021425.012

IMSLP/Petrucci Music Library: Free Public Domain Sheet Music (2015). Retrieved September 14, 2015. Retrieved from http://imslp.org/.

Jurkowski, E. (2010). "Clementi's "Progressive Sonatinas," Op. 36: Sonata semplice or Mediating Genre between Minuet and Sonata Design?" Intersections: Canadian Journal of Music, 31(1), 9-24. https://doi.org/10.7202/1009282ar

Kirby, F. (1995). "The Germanic Symphony of the Nineteenth Century: Genre, Form, Instrumentation, Expression." Journal of Musicological Research, 14(2), 193-221.

https://doi.org/10.1080/01411899508574705 
Kretschmar, H. (1919). Führer durch den Konzertsaal. (6 $6^{\text {th }}$ ed., Vol. 1). Leipzig: Breitkopf \& Härtel.

Shadko, J. (1981). The Symphony in Madrid. The Symphony 1720-1840: A Comprehensive Collection of Full Scores in Sixty Volumes (Ser. F, Vol. 4). New York: Garland.

Taruskin, R. (2005). Music in the Nineteenth Century. The Oxford History of Western Music (Vol. 3). New York: Oxford University Press. 